\title{
The Effect of Strategic Planning on Effectiveness and Efficiency of Human Resources Management
}

\author{
Abdelmoutaleb Mohammad Alamri
}

\begin{abstract}
The main purpose of this work is to examine the effect of strategic planning on Human Resources Management HRM practices. 200 survey questionnaires were sent to different employees and managers working in the hospitals sector in Jordan and only 169 questionnaires were received. Statistical Package of Social Sciences SPSS analytical software was used in this study to analysis the data and testing the hypotheses. The study examines the effect of strategic planning on HRM. The strategic planning analyzed as one construct while HRM practices have five constructs i.e. HRM planning; performance management; recruitment and selection; training and compensation. The results indicated that significant positive impact of strategic planning on HRM practices being analyzed in this study except for the performance management. Thus, the finding concluded that effective strategic planning will result in sufficient and effective HRM practices.
\end{abstract}

Keywords: strategic planning, human resource management, hospitals industry, Jordan

DOI: $10.7176 / \mathrm{EJBM} / 12-17-03$

Publication date:June 30th 2020

\section{Introduction}

All different kinds of business organizations in several industries encounter a complicated and intense competition in the current business environment wherein the strategic planning issue in different facets of the organization such as Human Resource Management (HRM) has an outstanding role in the success of these organizations and, therefore, business competition. Differently of other industries, the product of services organizations in the hospitals sector, for instance, are service experience, which they are characterized as intangible services and mostly dependent on direct communication between the employees and their daily customers. Therefore, HRM should be considered among organization planning strategies once they start to formulate such those strategies due to the critical role of HRM play a key role in developing the quality of the services and could maintain long rates of customer loyalty and satisfaction which also results positively to other measurements of organization performance (Baum, 2015). Therefore, the field of strategic planning associated with HRM in the available literature on services organization has increased mostly over the last near decades. Strategic planning connected to HRM mainly high light on how the planning could support the effectiveness and efficiency of HRM systems in terms to establish a sustainable competitive advantage for the organization. The motivation drive strategic planning and HRM study are to examine how the organizational strategic planning can reveal either a direct or indirect effect to HRM practices' effectiveness and efficiency (Triatmanto, 2019).

At present, the business has already begun to give more interest to HRM strategies and policies and the way of implementation to get a great level of competitive advantage as well remarkable performance in their business daily operations. The concept of HRM has arisen from the notion of implementing human resources management wisely and efficiently (Mitsakis and Aravopoulou, 2016). The departments of human resources management in the business are serving in different methods and ways for numerous aims like increasing rates of competition, managing effectively the international business, technological adoptions, operating in consistent with designed regulations, controlling organizations' activities and guarantee ethical matters and the best practices (Madera et al., 2017). The current human resources management sections are considered mostly a culture values and beliefs custodian of company goal also and regulations over overall the organization. However, the experts of HRM have important burden when they regulate and design strategic policy and plan which aims to reduce the uncertainties throughout the business environments.

Although strategic planning studies have expanded in current decades, there is a very little attempt on the effect of strategic planning on HRM practices in the contexts of the services industry and how it influences the activities of HRM (Vardarlier, 2016). The current paper shed lights on a thorough review of strategic planning area in the HRM literature, concentrating on the relationships between HRM effectiveness and strategic planning. Thus, the aim of this work is to provide a thorough, quantitative and literature review of the strategic planning and its effects towards achieving effective and efficient HRM systems and practises, investigating the different perspectives of various management levels in the services industry with main focus on the hospitals due to the high contribution of this sector in the national economy and the potential value-added can be achieved if more concern to strategic planning with HRM activities. As a new business and management concept, strategic planning is discussed widely with various variables and provided significant effective results aims to achieve the long-term objectives of the organizations. Therefore, the problem of this study is to identify the real effects of strategic planning on HRM practices in Jordanian hospitals sector. It also attempts to examine the most important problem 
that hospitals sector encounter while implementing a strategic plan. In doing so, the objectives are twofold: first, exploring the general related HRM material, stating the development of HRM second, providing quantitative implication and results and review the recent strategic planning of HRM functions with focusing on develop new emerging research directions and fill existed research gaps between the two concepts of relevant literature in regards to this research topic to provide also academic and practitioner recommendation and suggestion for future study.

\section{Literature Review}

The strategic planning until the early of 1980s in the last century was recognized as one of the most main functions of management in business organizations. Then, for a time, its significance has become more perceived resulted in shifting in the management methods in the contexts of improving quality, customizing, maintaining and implementing management functions in the whole organizations. However, the importance of strategic planning has emerged again and it is returning to its past critical role. The recently published works have conducted in different settings and fields through also many parties found that high level of management like executive, consultant, and business school academicians emphasized the importance of business strategy and perceived it as important management aspect which will still fundamental for the next years. Strategic planning can be described as a process whereby the goals of the organizations are developed and the operations have working to meet these goals are specified (Shields and Wright, 2017). The process aims to allocate the available resources to conduct operations. Conceptually, the process, as illustrated in Figure 1, starts with the organizations' missions and the identification of the organizations' long-term goals.

\section{Organizations Missions $\longrightarrow$ Long-Term Goals $\longrightarrow$ Short-Term Goals}

Figure 1. Strategy Relationship

Strategies are designed which result in the achievement of those organizational objectives and plans with short-term goals and objectives that are required to carry out the strategies. The strategic planning process is a customized, formalized and top-down direction process which is mainly focused on planning. The organization is composed of many business units and then different business functions. The logic and rational planning processes are those utilized each of these three strategy relationships in order to formulate strategies and then to integrate them into a combined body for the whole organization (Suarez et al., 2016).

Numerous studies examined the impact and relationships between strategic planning and HRM activities within different industries and organizations, and some of these studies indicated that both variables have a significant positive effect and relationship (Brewster, 2017) also found the efficiency of HRM in the effective organizational management in the crises. According to Grosser et al. (2016), which evaluated the strategic planning levels of the organizations and proved its effect on human resources management activities and therefore there is a need to develop dynamic organizational plan supported with a strategic perspective. Hence, the importance of strategic planning towards many facets of current business organization and the remarkable impact on HRM enforce those organization to focus and maintain this relationship in terms to keep this great effect and relationships among strategic planning and HRM practices, wherein the organizations can ensure that their business strategies associated with their human resources management activities are a match with the vision and strategy of their businesses (Elbanna et al., 2016). However, the growing interest among scholars in the concept of strategic planning has provided new contributions and implication in contexts to develop the human capital and assets through identifying the magnitude effect of strategic planning on human resources management operations in the organizations.

There are many basic functions and operation among all types of organizations and the human resources management is one of these major functions and management which its work is focused on all human resources management practices within it the overall relevant job and operations aspects since an employee's appointment in the organization until contract ending or termination (Abdelqader et al., 2018). Some of the studies have indicated that HRM had the main core for each operation of the business in all organizations and no organization can effectively manage and perform its operations and functions without great involvement and participation of its human resources management which considered also one of the eminent factors contributing in its success and increasing its competitive advantage which also requires effectively managing with the best methods, in addition, they indicated that HRM is carried out by many dimensions which summarize HRM main functions for example selection and appointment: the process which conduction interviews, selection and evaluation, Training process also a consequent process after hiring to ensure developing the capabilities of employee and decrease their skills to achieve their duties sufficiently. As well the incentive of human needs is also a great source of staff's motivation and can be a determinant for their behaviors; and some of the researchers add new emerging dimensions of HRM like empowerment and decision-making involvement (Assudani et al., 2016).

Moreover, the strategy of HRM looking for to manage the organizations sufficiently to their manpower and 
sought to maintain its marketing positioning in the business market. Prasad (2012) argued that organization with a premium mission and vision statements and organizational strategy are assumed to obtain developed related HRM strategy in handling their operation and strategy implementation. The study which used a cross-sectional approach combined qualitative and quantitative method data to analyze the results associated with the field of human resource strategies. The findings point out that the planning strategy pursued by the organizations is directly connected with the fulfilling needs of human resources management. Here, the capabilities of the employee should be trained alongside related skills to stand with a related control system which aims to attain the organizational objectives. On the other hand, as a study carried out by Noe (2013) aims to identify the potential influence of strategic planning on HRM and defines the strategic planning as a set of underlying methods and processes which are designed and implemented towards adapting and making the current situations in a way can reach desired outcomes. The study used a qualitative approach and collect the data through interviews proposed which the strategic planning can also describe as the process of using effective and sufficient sets of criteria and comprehensive evaluation to formulate, maintain and control HRM systems and finally enhance the organization's needs. The results concluded that strategic planning is one of the major methods to draw up the future for the organization and the best direction to get a desirable result. According to another study, strategic planning is also important to be noted that strategic planning describes the process that most organization respond to the attempts to of decision-making that related to allocating the found human resource. The results of Niehaus and her colleagues (2013) carried out research contended that emerging new civilization and phenomenon of globalization introducing with the adopting new technology in the several organizations have found prominent altering within the new business market. Their study which depended on the effect of strategic planning on organizational performance using survey questionnaires and suggested that one of the remarkable approaches that the organizations try to back their business effectiveness in the growing changing business landscape is by formulating dynamic strategic planning of HRM.

The concepts of effectiveness and efficiency could be implemented in HRM activities including these functions implemented by managers. Measurements of effectiveness and efficiency can also be performed to the performance of human resource. The measuring approaches also used to verify and assure the robustness of HRM efficiency and effectiveness within the organization (Wagner, 2019). In the context of strategic planning of human resource, the efficiency measures related outcomes achieved to particular human resource functions. The concept of efficiency is described in terms of outcomes attained relates to the resources input. Different practices and plans like training, recruitment, and compensation are investigated considering the outcomes achieved like costs of training and hiring. Effectiveness on the other hand, described in terms of the functions of HRM that support the outstanding performing of long term business processes and strategies. Practically, the organizations define the strategies of HRM which needed to manage critically the human resource issues which occur from the business environment. The significance of the human resources management issues and convenience of strategic planning may change based on the changing of priorities and situations (Wong, 2015). The focus on strategies is the issue that the definition of effectiveness in many organizations depends on, and the effectiveness measurements related results can be achieved to human resource issue and like the effect of HRM practices on the fulfilment of organizational goals. Findings of different operations and plans are investigated in terms of how well human resource processes are being managed.

The concepts of both efficiency and effectiveness are used as two different methods or ways to judge the operations of an organization, whether enterprise, government agency Efficiency term is primarily an industrial term which occurs in the early of last twentieth century (Quach, 2015). The terms efficiency and effectiveness are usually used in measuring productivity and performance interchangeable and as a synonym, associated with other terms such as competency, performance, and proficiency. However, in most decisions in modern management, the terms of efficiency and effectiveness hold diverse meanings. In the contexts of industrial engineering, a definition by Roberts states the concept of efficiency as the degree of the economy which the processes consume resources specifically time and money, otherwise, he also defines the concept of effectiveness as to how the process will actually accomplish the intended purpose. Another understanding to differentiate these two terms is the explanation which indicates that the efficiency is to do things rightly, and the effectiveness is to do the right things.

Organizational effectiveness is a factor measured highly among all organizations to evaluate its success and competitiveness compared to others. Therefore, there is no single and consent among scholars and theorists about the definition of effectiveness. Many attempts and models struggle to provide a unique definition of this concept have existed in the current management literature which includes the bureaucratic model which identify the effectiveness as a mean match the typical traits of a bureaucratic organization, another model indicated the effectiveness also a mean to achieve objectives of organizations, also this concept can be defined as using effectively the available important resources in the way to accomplish goals (Cameron, 2015). The strategic constituency model measures the effectiveness in the way to satisfy as much as significant stakeholders and provide high quality with both external and internal processes. On the other hand, the definition of efficiency is common and measured by several indicators of outputs. Similarly, the International Transport Forum (International 
Transport Forum, 2008) defined the concept of efficiency as "sets of combination aim to reduce costs and increase the benefits to society (p. 89)." From this point of view, can infer three particular definitions are described: "reduce inputs for the same output; having more output to improve the quality for the same input to increase in resources." Moreover, the definition of efficiency involves various meanings based on different perspectives, like technical efficiency, human efficiency, and whole efficiency. They focus to reduce the spending and maximize the capabilities and outputs of a given cost and resources (Choi and Jung, 2017).

Regarding the parameters of strategic planning, the foundations of strategic planning come in constructs identified by Phillips (1996) during his survey of the literature relating to the design of the strategic planning system. He describes four dimensions called: formalization which indicates a clear systematic procedure to attain great commitment; participation indicates improve communication and build up perspectives and functional direction of the organization; sophistication through using a wide range of management methods; thoroughness by using experiences from different management levels. Parameters of HRM, Al-Hawary and Nusair (2017) indicates that HRM is a construct analyzed through four factors which represent the dimensions of human resources management. Selection and appointment process which indicates the process related to plans and outcomes of selection. The training which is subsequent for selection and appointment process as HRM not only responsible to hire staff without train and develop them by design several training programs enable the staff to earn new skills and competencies could help to accomplish their tasks smoothly and effectively, it is a process to teaching new employees the major and basic skills they need to practice their work (Obaid and Eneizan, 2016). The process of training is concluded three significant factors indicated by learning, supporting and development that selected staff within an organization. Incentive: it is represented in the motivation of the employee which considered the main human needs which should be focused and act as an individuals motivation and the essential determinant for their attitudes in the organization, so incentives are sets of drivers which struggle to influence the employee behavior by fulfilling their basic needs and it represents the results of increasing human resources management productivity and competencies within the organization alongside other human resources management activities which training and regulating human resources management and manage them toward a particular objective.

Performance evaluation: is another important dimension of HRM process which also aims to evaluate and measure all factors and elements pertain to effective performance to shed light employee's contribution extent in productivity and performance which this includes groups of steps and procedures created to get an evaluation for each single unit performance in the company. Individuals' evaluation itself is an assessment of the organization's whole performance as it focuses on weaknesses and strengths points in the management operations in planning, organizing, controlling, maintaining and recruitment facets. Performance evaluation factor has two outcomes; an objective outcome which focuses on production quantity, quality, speed and objective achievement, and behavioral outcomes which also concentrate on the staff personal characteristics like abilities and willingness to learn and get benefits training (Jabbour and de Sousa, 2016).

Some studies have reported that different forms of strategic planning practices were utilized to a wide extent in their organizations. They also showed a moderation role and amount of effect of strategic planning in the activities related to human resources management (Yavitz, 2017). Obviously, the majority of the responses have a good handle of strategic planning methods while designing the HRM policies. Despite strategic planning operations look the very significant part of company operations today, outcomes revealed the majority of present executives had dealt the strategic operations used in their companies for many years. As well they see strategic planning as a vital component of corporate survival and life. The practitioners of HRM and strategy planners expand their judgment to the contributions of the strategic planning processes to the whole organization performance of their corporates. In addition, most of the point of view of the strategic experts declared that they found an effective role of the strategic planning process of their organizations to their human resource asset (Brewster, 2017). Also, they found strategic planning contribute to the total effectiveness of the organization.

There are several HRM practices which the most of human resources management departments practice those activities daily basis, therefore, they need to have more attention in order to sustain and survive the organization among the intensely competitive business environment. In the current study, the HRM practices which are considered are HRM planning, Recruitment and Selection, Performance Management, Training and Compensation and these activities could be planned and designed among the strategic planning of the organizations. The main reason to identify and selecting these practices is that they would provide high sustainability to HRM functions. Strategic planning of HRM is one of the innovative contemporary concepts which many researchers and HR practitioners have examined and reviewed with some numerous factors. Strategic planning of HRM is the comprehensive process of several human resources management practices and duties pertinent to plan and develop a qualified employee. It also contributes to the overall organizational effectiveness and associated with the organization's strategic objectives. Strategic planning of HRM appears in a complicated and rapid changes business environment within the organizational setting (Khan et al., 2015). An important trend today's business is for HRM practitioners to design a strategic base of the job planning and recognize the significant connections between organizational objectives and HRM strategies. Recruitment and selection are also one of the noteworthy 
functions of HRM whereas the competition is increasing between the companies, so the selecting and recruiting the talented, qualified and skilled workforces become added important. Consequently, all companies have widely hunted potential candidates to participate in achieving the vigorous functions of the HRM. Companies do not only need to design a hunting strategy but also have to retain current employees (Ekwoaba et al., 2015).

A global crisis like COVID-19 is hitting all the business hardly in a short period of time; as well it could also change the face of the HRM role in the world workplace dramatically. Since this pandemic occurred its first outbreak in Chinese city Wuhan in last December, more than 115,000 individuals have been infected by this virus which spread globally. With increasing of the death rates and reaching thousands and the business conditions altering, businesses are filled with cautionary and more concern. Whilst both governments and organizations are starting to design dynamic action plans and contingency process, but the uncertainty is still found and can't predict the coming day's consequences. As it is usually the case, human resources departments will see the effects immediately (Vardarlier, 2016). However, the potentially lasting effects of Coronavirus on the strategic planning of human resources which a lot of companies feel and face this critical challenge in the coming future, and encourage them to establish up a more likely permanent remote working days while this health phenomenon potentially continues to spread worldwide and take a long time until businesses recovery. Therefore, crucial challenges of the current businesses have begun to adapt with this situation and start to increase in remote working hours in order to quickly and effectively avoid a lengthy period of declining the productivity and survival. Thus, some businesses have better prepared their human assets than others in a way to less impact that they will feel (Hosie and Pforr, 2016). Determining the aim of workforce planning has become important to align the needs of the businesses with the existed workforces' abilities and organizational capabilities as well as the external motivation of the businesses on a continuous basis. Now economics and public health systems definitely have a continuous and sudden influence on the businesses operations and this requires of business to have flexible roles, tasks and work systems even performance management.

However, Performance management indicates to the large diversity of functions, processes and procedures designed to support developing the employees' performance. These policies and plans begin the performance appraisal systems and they include productive feedback, objectives setting, and training, as well as remuneration and reward systems. Therefore, performance management systems have started with performance appraisal as a launching point and then concentrate on beautifying the individual's performance in a way matching with the strategic objectives and with the leading goal of improving the organizational performance (DeNisi and Murphy, 2017). Managers nowadays must be informed about struggling of managing remotely the performance of large numbers of employees for an unexpected and extended period would undoubtedly largely influence the organizational performance. As a starting point, professionals have suggested starting by determining something which is often micro-manage whereas the most employees aren't used to working remotely, so the organizations based on the experts should provide the workplace environment which allows accomplishing the tasks remotely and motivate the employees to work in a less ideal situation. In many situations, the employees surely have their own social responsibilities like their families and children who need more care at home. Moreover, the employees who are stuck at home must find various methods and ways of still positive, work tasks oriented and more productive (Correia et al., 2015).

Training as a process of providing qualified armed skills workforces with innovative and creative ideas and competencies to be implemented in the organization functions is considered one of the vital functions of HRM that need to be concerned more to perform the duties and responsibilities in a talent way. Exploring the role of training on firm performance and strategic planning of this function among different sectors was inspire of some studies which revealed generally, the training develops the employee engagement and supports improving the performance of the HRM. Furthermore, the factor of training also increases the rates of employee motivation and enthusiasm towards the work. Shortly, the strategic planning and training connected with job performance have significant interrelationships (Manzoor et al., 2019). Compensation refers to both internal and external rewards which the employees receive in substitute of their works. According to some scholars, the element of compensation often consists of the agreed salary, incentive or bonus, and any monetary benefits linked to their jobs and positions in the firm. In a similar way, Berber and Slavić (2016) discussed the company's compensation and confirmed that compensation would include both direct and indirect types of compensation. The direct compensation indicates main compensation like wage and payoff. Differently, indirect compensation includes a set of monetary benefit offered to employees like health insurance and social security subscription. The compensation can be argued the most critical motivation factor when it indicates to attract and keep the creative and talents. Based on the literature, the study addresses the main hypothesis as follow:

H1: There is a significant effect of strategic planning on HRM activities in the Jordanian hospital sector. There are sub hypotheses under this main hypothesis as follow:

H1a: There is a significant effect of strategic planning on HRM planning.

$\mathrm{H} 1 \mathrm{~b}$ : There is a significant effect of strategic planning on Recruitment and Selection.

H1c: There is a significant effect of strategic planning on Performance Management. 
H1d: There is a significant effect of strategic planning on Training.

H1e: There is a significant effect of strategic planning on Compensation.

\section{Research Methodology}

This research conducted a descriptive and quantitative method research design which focuses to shed light the possible effect of strategic planning to HRM practices in the hospital sector in Jordan. However, the researcher synthesized the related data used in this whole study. Both secondary and primary data were collected for the current study. The primary data were collected by a survey questionnaire distributed to the targeted sample to obtain their agreement or disagreement towards sets of statements regarding the variables of the study being examined in this work. Secondary data such as theoretical background and previous relevant studies also were gathered from different sources of new academic journals connected to the area of this study (Mohajan, 2018). The author in the section of methodology outlines the research design and approach as well the methods of selecting the sample and statistical methods used to test and analyze the hypotheses and reliability of the study instrument which is the questionnaire which also designed based on related reliable valid resources available in several academic studies. This study includes as mention before a quantitative technique which is a technique used and collects numerical data and particular statistical analysis methods to draw a valuable conclusion and recommendation. The researcher came in touch with respondents and asked them to cooperate and respond to the current work after explaining the purposes and the aims of the study. Regarding the population and sampling technique used in this study, the unit analysis is an individual level which includes all senior levels of employee working departments of human resource in the hospitals working in Jordan. The number of samples was attained from those departments in different hospitals.

Out of the numbers of the study sample, total of (189) senior-level employees are randomly selected by using simple random sampling technique to represent the population of the study who work in the human resources management departments in the selected hospitals as senior-level employees and the questionnaire also designed based on five Likert Scale which is the most commend measurement tool used in social studies which consist of five responses to the statement provided in the questionnaire as follow: strongly disagree, disagree, not sure, agree, strongly agree, and given them a weight. The higher of a mean represent a higher response of agreeing on the statement. Also, the questionnaire was also divided to different sections which include the section of demographic variables such as gender, education level, years of experience, the second section includes the items of each variable to measure the constructs involved in the study which also divided to the items which aim to measure the HRM dimensions from the point view of the sample which adapted from some related reliable studies (Ieva et al., 2012; Prasad, 2012; Noe, 2013). Strategic planning construct has been measured by 7 items, on the other hand, the HRM construct also divided into a group of dimensions namely: HRM planning; performance management; recruitment and selection; training and compensation measured by 4 items for each.

As a prior step to check the validity of study's instrument, a number of questionnaires were sent to a number of reviewers who experts in the area of the study, university academicians who also specialists in the HR field to evaluate the ability of measurement scales in measuring the concepts of the study and their extent of clearance. According to their feedback and corrections, some editing was done; some statements were skipped, new of them were added and others were rewritten again to assure the reliability of the questionnaire in measuring the intended variables. Another step of preparing the questionnaire before final distribution, some statisticians also checked the questionnaire in terms of its design, style, and whether the type and numbers of items were adequate for further statistical analysis. In addition, a pilot study was conducted with ten respondents to check the extent of items clarity and relatedness of the items to their factors as well to check the validity and reliability of the study instrument through Cronbach's alpha value which used to estimate the internal consistency of the measurement (Taherdoost, 2016). Wherein all dimensions achieved the remarkable value of reliability (above 0.70) (Taber, 2018). The Cronbach's alpha for HRM factors and the strategic planning factors were 0.79 and 0.81 respectively. This result represents that the reliability coefficient for all factors was above (0.70). This also indicates that the study instrument is reliable and valid for further analysis and research. The results are shown in Table 1.

Table 2

\begin{tabular}{|l|l|l|}
\hline Variable name & No of items & Cronbachalpha \\
\hline HRM & 20 & 0.79 \\
\hline Strategic planning & 16 & 0.81 \\
\hline
\end{tabular}

\section{Research Results and Discussion}

This section discusses the results attained by the study instrument, called the quantitative method analysis of the collected data from the survey questionnaire. This section includes an analysis of the descriptive statistics of the study sample, and the hypotheses testing with a valid interpretation of the findings. Table 2 provides the demographic analysis of study sample which consisted of (189) senior-level employees from both genders and different experiences as well as educational levels. 
Table 2. Characteristic of the Respondents $(n=189)$

\begin{tabular}{|c|c|c|}
\hline Items & \multicolumn{2}{|c|}{ Frequency percentage } \\
\hline \multicolumn{3}{|l|}{ Gender } \\
\hline Male & 65 & 34.4 \\
\hline Female & 124 & 65.6 \\
\hline Total & \multicolumn{2}{|l|}{189} \\
\hline \multicolumn{3}{|l|}{ Experience } \\
\hline$<5$ years & 22 & 11.6 \\
\hline 5-10 years & 20 & 10.6 \\
\hline$>10$ years & 147 & 77.8 \\
\hline Total & \multicolumn{2}{|l|}{189} \\
\hline \multicolumn{3}{|l|}{ Educational levels } \\
\hline Bachelor & 90 & 47.6 \\
\hline Master & 83 & 43.9 \\
\hline Ph.D & 16 & 8.5 \\
\hline Total & \multicolumn{2}{|l|}{189} \\
\hline
\end{tabular}

Analyzing respondent characteristics data (Table 2), the respondents were fundamentally female $(65.6 \%)$ which this result can be interpreted the majority of the employee working in the hospitals were female which indicate the preferences of this gender for humanitarian fields like nursing and medical specializations. However, respondents' experiences ranged from $11.6 \%, 10.6 \%$ and $77.8 \%$ for less than 5 years which indicates the most of sample have long experiences and the rate of turnover is low, and approximately $47.6 \%$ of participants were Bachelor, 43.9 master holders and $8.5 \% \mathrm{PhD}$ holders which indicated a diversity of educational levels of the respondents involved in this study which also revealed the staff working in the hospitals should be highly educated due to the sensitivity of this sector which belonging people's lives which require a high degree of professionalism and experiences.

This section tests the suggested hypotheses which represent the effect of strategic planning on HRM practices. Simple linear regression was used to perform this analysis and test the hypotheses. The result either to reject or accept the hypothesis was depending on the certain rules: accept the null hypothesis once the significance level is equal or less than 0.05 . Reject the null hypothesis once the significance level is greater than 0.05 .

H1: There is a significant effect of strategic planning on HRM activities in the Jordanian hospital sector. Table 3 displays the statistical outcomes of the main effect of strategic planning as an independent construct on the overall HRM practices.

Table 3 strategic effect on overall HRM practices

\begin{tabular}{|l|l|l|l|l|l|l|l|l|}
\hline Hypothesis & $\mathrm{R}$ & $\mathrm{R}^{2}$ & $\mathrm{df}$ & $\mathrm{f}$ & beta & $\mathrm{T}$ & Sig. & Decision \\
\hline H1 & 0.521 & 0.272 & 188 & 69.836 & 0.521 & 5.979 & 0.000 & Accept \\
\hline
\end{tabular}

Table (3) indicates that strategic planning significantly affects the overall HRM practices. The value of R2 is (0.272), which indicates that strategic planning explains $(27.7 \%)$ of the variance of total HRM activities. The greater value of $\mathrm{R}(0.521)$ revealed that the study model has a positive effect. So, the null hypothesis fails to accept, and the alternative hypothesis indicates a significant effect of strategic planning on HRM practices. As demonstrated by the results, strategic planning variable has a positive effect on the sufficient and effectiveness of HRM activities which indicates the interest of the hospitals in Jordan to use the strategic planning approach to ensure effective applying HRM. The surveyed hospitals management highly considered the HRM functions to effectively achieve survival and long term sustainability, profitability and other objectives which in line with their visions. These findings are consistent with some other international findings which addressed the effect of strategic planning on HRM processes (Aryanto et al., 2015).

H1a: There is a significant effect of strategic planning on HRM planning. To test this hypothesis, the linear regression was conducted and the following statistical results have shown (Table 4).

Table 4. Effect of Strategic Planning on HRM planning

\begin{tabular}{|l|l|l|l|l|l|l|l|l|}
\hline Hypothesis & $\mathrm{R}$ & $\mathrm{R}^{2}$ & $\mathrm{df}$ & $\mathrm{F}$ & Beta & T & Sig. & Decision \\
\hline H1a & 0.592 & 0.350 & 188 & 100.846 & 0.592 & 10.407 & 0.000 & Accept \\
\hline
\end{tabular}

Table 4 shows that the effect size of strategic planning and the variation value explained the variable strategic planning of the variation in the activity of HRM planning was (35\%), the F value is (100.846), the significance level is $(0.000)$. Since the significance level is less than $(0.05)$, the study not accepts the null hypothesis and accepts the alternative hypothesis which states: There is a significant effect of strategic planning on HRM planning at Jordanian hospitals. The explanation of this finding may be described in terms of the effective role of strategic planning in designing HRM planning which implies establishing long term plans associated with HRM and consistent with recent growing demands of effective planning of HRM.

H1b: There is a significant effect of strategic planning on Recruitment and Selection. To test this hypothesis, the 
linear regression was conducted and the following statistical results have shown (Table 5). Table 5. Effect of Strategic Planning on Recruitment and Selection

\begin{tabular}{|l|l|l|l|l|l|l|l|l|}
\hline Hypothesis & $\mathrm{R}$ & $\mathrm{R}^{2}$ & $\mathrm{df}$ & $\mathrm{F}$ & Beta & $\mathrm{T}$ & Sig. & Decision \\
\hline H1b & 0.720 & 0.518 & 188 & 200.780 & 0.720 & -2.910 & 0.004 & Accept \\
\hline
\end{tabular}

Table 5 illustrates that the effect size of strategic planning and the variation value explained the variable strategic planning of the variation in the activity of recruitment and selection was (52\%), the F value is (200.780), the significance level is (0.004). Since the significance level is lower than (0.05), so that, the study fails to accept the null hypothesis and accept the alternative hypothesis which states: There is a significant effect of strategic planning on recruitment and selection at Jordanian hospitals. The interpretation of this result described the role of strategic planning in vary the methods of recruitment and selection while hiring the talent employee to assure the qualified and skilled manpower was selected to support the hospitals' mission and vision.

H1c: There is a statistically significant effect of strategic planning on performance management. To test this hypothesis, the linear regression analysis was conducted and the following results have shown (Table 6).

Table 6. Effect of Strategic Planning on Performance Management

\begin{tabular}{|l|l|l|l|l|l|l|l|l|}
\hline Hypothesis & $\mathrm{R}$ & $\mathrm{R}^{2}$ & $\mathrm{df}$ & $\mathrm{F}$ & Beta & t & Sig. & Decision \\
\hline H1c & 0.129 & 0.017 & 188 & 3.181 & 0.129 & 8.976 & 0.76 & Reject \\
\hline
\end{tabular}

Table 6 reveals that the effect size of strategic planning and the variation value explained the variable strategic planning of the variation in the activity of performance management was $(2 \%)$, the $F$ value is (3.181), and the significance level is $(0.76)$. Since the significance level is greater than $(0.05)$, the study accepts the null hypothesis and reject the alternative hypothesis which states: There is no significant effect of strategic planning on performance management at Jordanian hospitals. This result indicates the effect of strategic planning is weak on management the performance which interprets another vital factor would develop this factor rather than strategic planning.

H1d: There is a statistically significant effect of strategic planning on Training. To test this hypothesis, the linear regression was conducted and the following statistical results showed (Table 7).

Table 7. The Effect of Strategic Planning on Training

\begin{tabular}{|l|l|l|l|l|l|l|l|l|}
\hline Hypothesis & $\mathrm{R}$ & $\mathrm{R}^{2}$ & $\mathrm{df}$ & $\mathrm{F}$ & Beta & $\mathrm{t}$ & Sig. & Decision \\
\hline H1d & 0.161 & 0.026 & 188 & 4.966 & -0.161 & 12.491 & 0.027 & Accept \\
\hline
\end{tabular}

Table 7 shows that the effect size of strategic planning and the variation value explained the variable strategic planning of the variation in the activity of Training was $(2 \%)$, the $F$ value is (4.966), the significance level is (0.027). Since the significance level is less than (0.05), the study rejects the null hypothesis and accept the alternative hypothesis which states: There is a significant effect of strategic planning on training at Jordanian hospitals. This result indicates the effect of strategic planning is positively influence the training of the employee which supports their capabilities and skills in a way to beautify the whole organizational performance of hospitals in Jordan.

Table 8. The Effect of Strategic Planning on Compensation

\begin{tabular}{|l|l|l|l|l|l|l|l|l|}
\hline Hypothesis & $\mathrm{R}$ & $\mathrm{R}^{2}$ & $\mathrm{Df}$ & $\mathrm{F}$ & Beta & $\mathrm{t}$ & Sig. & Decision \\
\hline H1e & 0.675 & 0.456 & 188 & 156.053 & 0.675 & -2.118 & 0.000 & Accept \\
\hline
\end{tabular}

Table 8 shows that the effect size of strategic planning and the variation value explained the variable strategic planning of the variation in the activity of compensation was (45\%), the F value is (156.053), the significance level is $(0.027)$. Since the significance level is less than $(0.05)$, the study rejects the null hypothesis and accepts the alternative hypothesis which indicates: There is a significant effect of strategic planning on compensation at Jordanian hospitals. This result indicates the effect of strategic planning is positively impact the compensation which also supports their motivation and increases their enthusiasm to show long term commitment and retention within their organizations.

\section{Conclusion}

This research discussed the effects of strategic planning and the practices of HRM on a sample of healthcare organizations in Jordan. The objective of this work was to create the importance of strategic planning policies towards several aspects of the human resources management departments, whether it was an administrative function or complicated two-way integrated functions. Furthermore, the study researched there were statistically significant effects of strategic planning among different respondents' levels against HRM activities. It is concluded that the relationships between strategic planning and HRM functions were at the significant levels, even though the findings provided should be considered as the survey questionnaire approach which was used to the study sample, also it provided valuable results because the possible different responses of the sample as well the cultural environment of the population that the survey was conducted at (hospital in Jordan).

This study also revealed whether any effects found between strategic planning and HRM human resource management construct and strategic matters of the business entities. The analysis reported the first hypothesis was 
supported that Jordanian hospital sector is believing the significant of strategic planning among their HRM practices. It is mandatory to convince the organisational strategic policymakers to redesign their strategies based on the growing changes of both personnel and business demands. As the companies adopting strategic planning of HRM in terms to generate outstanding competitive advantage in Jordan, the contemporary modern methods using in the current organisations should formulate their strategies to integrate the human resources management as a strategic component in the mission of the organizations. It was also showed from the analysis that strategic planning and HRM variables go together in the same way with higher intentions of strategies makers to determine planning levels and HRM effectiveness. This finding clearly proposes to some of the related Jordanian organisations that powerful strategic planning and development of HRM could support them to size the advantages obtained from applying careful planning of HRM strategies. On the other hand, the organisational strategy design could be aligned sufficiently integrated together through the HRM and strategic planning. The results of the study support the significant effect of strategic planning on the HRM of the hospitals. The results uncover the facts that motivations and human resource planning practices are positively connected with the strategic planning and it was a great relationship. Finally, it is mainly debated that managements of the organizations should support the drivers of developing the effectiveness of human resources management through involving strategic planning factors to greater human resources management performance as the result could lead to greater productivity.

This research has discussed five practices of HRM: human resources management planning, selection/recruitment, performance management, training and compensation. The results revealed that HRM in Jordanian hospitals has received some attention to these activities and the role of strategic planning in supporting these functions in the direction to accomplish the overall organizational objectives. The performance management and compensation systems can be sufficiently used for monitoring and motivating hospitals staff in their functions and evaluate their activities in accordance with the strategic planning and HRM of the hospitals in Jordan. On the other hand, the process of recruitment and selection is highly needed more effective concern. In Jordanian hospitals, the expenditures and time spent on training to develop the organization are considered a useful and necessary HRM function would also strengthen the efforts of developing organizational productivity. The study has also provided a quantitative review with the literature of strategic HRM from the general management literature and the hospital sector literature, and it outlined the gaps between the two bodies of constructs and make recommendations for future studies like showing the need to investigate strategic HRM at the different organizational levels and declare the importance to examine an overall theoretical framework connecting organizational strategic HRM and the whole organizational performance.

As similar to any other studies, the study design is restricted to some limitations which need to be avoided in further future studies. This research is a valued examination of the effects of strategic planning towards HRM different practises in the hospital sector in Jordan. Therefore, a further study is required to scrutinize the validity of the results in a various larger setting or context. Second, the researcher selected the sample of the study as the employees of only private hospitals rather than including the public health sector in Jordan. The reason behind delimitate this study is the vital role of the effectiveness of public sector in the national economy and gross domestic product GDP and the possible contributions which come from forming dynamic strategic planning with HRM activities to draw up an outstanding attraction of more revenues and profitability for the organization through a great package of human resources management development. Also, this research was conducted in Amman city due to the majority of the hospitals are working and placed in this city and constraint both the effort and time in data collection.

\section{References}

1. Abdelqader, A. A., Chao, H. S., Mohammad, E. B. and AL kharabsheh, K. (2018). Explore the relationship between human resource management practices and the consequences for emotional labor of insurance agents in the Jordanian insurance industry. Cogent Business \& Management, 5(1).

2. Al-Hawary, S.I.S. and Nusair, W.K.I., 2017. Impact of human resource strategies on perceived organizational support at Jordanian public universities. Global Journal of Management and Business Research.

3. Aryanto, R., Fontana, A. and Afiff, A.Z., 2015. Strategic human resource management, innovation capability and performance: An empirical study in Indonesia software industry. Procedia-Social and Behavioral Sciences, 211, pp.874-879.

4. Assudani, R. Khayat, I. Cunningham, M. and Kilbourne, L. (2016). Creating and scaling a social innovation, Case study of Support My School. International Journal of Social Entrepreneurship and Innovation, 4(1) p37-53.

5. Baum, T., 2015, Human resources in tourism: Still waiting for change? A 2015 reprise. Tourism Management, 50, pp.204-212.

6. Berber, N. and Slavić, A., 2016. Human resource (HR) outsourcing in European compensation management in the light of CRANET research. ActaPolytechnicaHungarica, 13(3), pp.207-225.

7. Brewster, C., (2017). The integration of human resource management and corporate strategy. In Policy and 
practice in European human resource management. Routledge, 22-35.

8. Cameron, K., 2015. Organizational effectiveness. Wiley Encyclopedia of Management, pp.1-4.

9. Choi, N. and Jung, K., 2017. Measuring Efficiency and Effectiveness of Highway Management in Sustainability. Sustainability, 9(8), p.1347.

10. Correia, T., Dussault, G. and Pontes, C., 2015. The impact of the financial crisis on human resources for health policies in three southern-Europe countries. Health Policy, 119(12), pp.1600-1605.

11. DeNisi, A.S. and Murphy, K.R., 2017. Performance appraisal and performance management: 100 years of progress?. Journal of Applied Psychology, 102(3), p.421.

12. Ekwoaba, J.O., Ikeije, U.U. and Ufoma, N., 2015. The Impact of Recruitment and Selection Criteria on Organizational Performance.

13. Elbanna, S., Andrews, R. and Pollanen, R. (2016). Strategic planning and implementation success in public service organizations, Evidence from Canada. Public Management Review, 18(7), 1017-42.

14. Grosser, T., Assudani, R., Taylor, W., Gladstone, E. and Mehra, A. (2016). Employee perceptions of network change following an organizational change. Academy of Management, 2016(1): 17005.

15. Hosie, P. and Pforr, C., 2016. Human resource development: Proactive preparation to manage crises. In Crisis Management in the Tourism Industry (pp. 93-108). Routledge.

16. Ieva, N., Roman, P., \&Tatjana, M. (2012). Strategic Planning and Management in Public and Private Sector Organization in Europe: A Comparative Analysis and Opportunities for Improvement. European Integration Studies, 6.

17. International Transport Forum. Transport Infrastructure Investment Options for Efficiency: Options for Efficiency; OECD Publishing: Paris, France, 2008.

18. Jabbour, C. J. C. and de Sousa, J. A. B. L. (2016). Green human resource management and green supply chain management, Linking two emerging agendas. Journal of Cleaner Production, 112: 1824-33.

19. Khan, Q.I., Shamsudin, A.S. and Ismail, M.S.S.S., 2015. The Influence of Career Planning and HRM Practices on Career Success of Faculty Members in Public Sector Universities of Pakistan. human resource management (HRM), 9 .

20. Madera, J. Dawson, M., Guchait, P. and Belarmino, A., 2017. Strategic human resources management research in hospitality and tourism. International Journal of Contemporary Hospitality Management.

21. Manzoor, F., Wei, L., Bányai, T., Nurunnabi, M. and Subhan, Q.A., 2019. An examination of sustainable HRM practices on job performance: An application of training as a moderator. Sustainability, 11(8), p.2263.

22. Mitsakis, F. and Aravopoulou, E. 2016. The impact of the economic crisis upon human resource development (HRD): evidence from two Greek banks. International Journal of Human Resource Development: Practice, Policy \& Research, 1(2), pp.67-82.

23. Mohajan, H.K., 2018. Qualitative research methodology in social sciences and related subjects. Journal of Economic Development, Environment and People, 7(1), pp.23-48.

24. Niehaus, R. J., Price, K., \& Human Resource Planning Society. (2013). Bottom Line Results From Strategic Human Resource Planning. New York. Plenum Press.

25. Noe, R. A. (2013). Human Resource Management: Gaining a Competitive Advantage. New York: McGrawHill/Irwin.

26. Obaid, T.F. and Eneizan, B.M., 2016. Transfer of training and post-training on job performance in middle eastern countries. Review of Public Administration and Management, 400(3786), pp.1-11.

27. Papke Shields, K. and Boyer Wright, K., 2017. Strategic planning characteristics applied to project management. International Journal of Project Management, 35(2), pp.169-179.

28. Phillips (1996). "Organisational Strategy, Strategic Planning Systems Characteristics, and Business Performance in the UK Hotel Sector." Ph.D. thesis, Cardiff Business School

29. Prasad, K. (2012). Strategic Human Resource Development: Concepts and Practices. New Delhi: PHI Learning.

30. Quach, A.H., 2015. Improving Competitiveness for ABC HR Consulting Company Through The Application of The Balanced Scorecard.

31. Suarez, E., Calvo-Mora, A. and Roldán, J., 2016. The role of strategic planning in excellence management systems. European Journal of Operational Research, 248(2), pp.532-542.

32. Taber, K.S., 2018. The use of Cronbach's alpha when developing and reporting research instruments in science education. Research in Science Education, 48(6), pp.1273-1296.

33. Taherdoost, H., 2016. Validity and reliability of the research instrument; how to test the validation of a questionnaire/survey in a research. How to Test the Validation of a Questionnaire/Survey in a Research (August 10, 2016).

34. Triatmanto, H., 2019. Reward System as a Strategic HRM Determining Work Productivity in Hospitality Organization.

35. Vardarlier, P., 2016., Strategic approach to human resources management during crisis. Procedia Social and 
Behavioral Sciences, 235(10), pp.463-472.

36. Wagner, J.M., 2019. Effectiveness and Efficiency of Disclosure: A Preparer's Perspective. Schmalenbach Business Review, 71(2), pp.271-278.

37. Wong, W.P., Soh, K.L., Le Chong, C. and Karia, N., 2015. Logistics firms performance: efficiency and effectiveness perspectives. International Journal of Productivity and Performance Management.

38. Yavitz, B., 2017. Human Resources in Strategic Planning. In Executive Talent (pp. 49-70). Routledge. 